Journal of Engineering and Applied Sciences 14 (Special Issue 5): 9066-9072, 2019

ISSN: 1816-949X

(C) Medwell Journals, 2019

\title{
Study on the Circular Perforations Effect in the Rectangular Fins on Convection Heat Transfer
}

\author{
${ }^{1}$ Aram Mohammed Ahmed, ${ }^{2}$ Mohammed Ghazy Habbeb and ${ }^{1}$ Iesam Jondi Hasan \\ ${ }^{1}$ Department of Refrigeration and Air-Conditioning Engineering, Technical College of Kirkuk, \\ ${ }^{2}$ Department of Environment and Pollution Engineering, Technical College of Kirkuk, \\ Northern Technical University, Kirkuk, Iraq
}

\begin{abstract}
The study displayed the heat transfer in a rectangular perforated fin plate by natural convection type, experiments produced through in an experimental facility designed and built a unique device for this study. And simulated with ANSYS program. The fins that used in this study including five types, the first one without perforated and the perforations were used with the remains fins by different shape as circular perforation these fins perforation by a different number of circles $(1,2,4$ and 8 circles) the cross-section area is same for all perforation's fins $\left(28.26 \mathrm{~cm}^{2}\right)$ for all perforated fin. These perforations distributed on 1 circle have a $60 \mathrm{~mm}$ diameter and after that divided to 2 circles have diameter $30 \mathrm{~mm}$, the 2 circles also divided to 4 circles have diameter $15 \mathrm{~mm}$ and the last one has 8 circles with $7.5 \mathrm{~mm}$ diameter is produced from divided the 4 circles perforated fin. The experiment is processed for different power is ranged from $(30,60$ and $90 \mathrm{~W})$. The results for practical side shows the temperature drops along the length, the temperature dropped in non-perforated fin was $\left(31.9-28^{\circ} \mathrm{C}\right)$ at $30 \mathrm{~W}$ but for perforated fin maximum drop was $\left(31.9-27.5^{\circ} \mathrm{C}\right)$ for one circle perforated fin also observed the temperature drop at $60 \mathrm{~W}$ along the non-perforated fin was $\left(86.6-76^{\circ} \mathrm{C}\right)$ but for perforated fin maximum drop was $\left(86.6-74.3^{\circ} \mathrm{C}\right)$ at one circle perforated. The last one was at $90 \mathrm{~W}$ for non-perforated fin was $\left(105.9-94.48^{\circ} \mathrm{C}\right)$ but for perforated fin was from $\left(105.9-89.9^{\circ} \mathrm{C}\right)$.
\end{abstract}

Key words: Rectangular fins, circular perforation, distribution of temperatures, heat transfer, experimental, cross-section

\section{INTRODUCTION}

The small surface is found adequate to heat transfer the required quantity of heat that leads to lower temperature and coefficient of heat transfer convection, the surface is known as fins that used for increasing the transfer of heat to the surrounding. This practice invariably is found necessary in heat transfer between a surface and air as the heat transfer coefficient is rather low in this case, the finned surface is widely used in industrial-like as economizers, radiators of air conditioning device and car, air-cooled engine, electric motor and transformers (Rajput, 2009). The another studied aimed to study the enhancement the convection heat transfer with fin by using rectangular perforation in rectangular fin with a high to a wide ratio of two has been checked using the method of finite element technique. The result was showed that, for a certain range of rectangular dimension and distance between perforations, there is an augmentation in heat loss and a reduced in weight over that of the equal solid one. Also, the heat transfer improvement of the perforated fin increases as the fin thickness, so with increasing thermal conductivity the heat transfer improves (Al-Essa et al., 2009). The triangular perforation in rectangular fin analyzed mathematically by this study, it used the dimension and thermal properties and equivalent with a solid one, the triangular perforated enhancement the heat transfer and value of improvement changed to fin thickness and thermal conductivity. The loss of heat is improvement with the perforated fin and have strong relationships with perforated dimension and lateral spacing, the maximum value when it has the best spacing. The perforation of fins enhances heat dissipation rates and at the same time decreases the expenditure of the fin material (AlEssa et al., 2009). One of the researchers studied the effect of an increase in the number of circular perforations. His experiment used the perforated fin staring from 24 circular perforations with increase by 8 perforated for each fin until 56 fins, the results showed the heat transfer rate increase also, the coefficient of heat transfer increases when the perforations number increased and the value for

Corresponding Author: Aram Mohammed Ahmed, Department of Refrigeration and Air-Conditioning Engineering, 


\section{J. Eng. Applied Sci., 14 (Special Issue 5): 9066-9072, 2019}

lower temperature with the perforated fin is large than when compare with non-perforated fin. The rectangular perforated was used with rectangular fin and compared with the solid one by considering the parameters geometrical dimension and thermal properties. The results view that for limit values of a rectangular hole, the openings of heat loss of the perforated fin are increased in the same ratio for solids. The size of the heat loss improvement depends on thermal conductivity for plate used in the experiment, thickness, hole dimensions, lateral distance and longitudinal distance. The bending of the fins boosts heat dissipation while at the same time reducing fin weight (Al-Essa, 2012). More of research focused on improvement the fin effectiveness during increase the perforation or increase number of perforation and used different shape of fins and spacing between fins to get best one of temperature drop and heat transfer rate. One of the researcher studied the effect of shape perforation on fins in this used some different shape like circle triangle, square and hexagon by design the instrument in the lab, the best temperature drop and heat transfer coefficient was for triangle shape (Jassem, 2013). Another research focused on experiment analysis to study the turbulent flow type of heat transfer activity of rectangular fin. Both flat and circular perforation along the length of fins. It used different size of hole and number of perforations with horizontal wind tunnel provider with a forced air that loss due to radiation and convection is taken into account through computing and this used to compare with solid fins. Five different types of fins used in the experiment with a different parameter like Nusselt number, heat transfer coefficient, thermal resistance, efficiency and effectiveness with varying Reynolds number. The Nusselt number and heat transfer coefficient, the pressure drops increases with increasing Reynolds number for all fins but perforated fins show the higher value of Nusselt number and heat transfer coefficient and lower value of pressure drop than solid fins. The values of thermal resistance, efficiency effectiveness and pressure drop in general decreases with increasing Reynolds number for all fins. It's found that more and large perforation, thermal resistance and dimension less, pressure drop decreases where efficiency and effectiveness increases (Ehteshum et al., 2015). The perforation in the fin lead to increase the heat transfer of the fin, so, perforation in the fins is suggested for high thermal performance by use plate with area of triangular cross-section fins in staggered offset this study made for four types of perforated fins and four types of solid fins in the duct have rectangular cross-section area and analysis the air is entered to the duct with $5 \mathrm{~m} / \mathrm{sec}$ velocity its discover decreasing in rate of heat transfer depend on increasing the spacing ratio for fins and the distribution of temperature that perforated fins its cool faster than the flat fins, for the same source of heat input of $900 \mathrm{~W}$ of fins and fin arrangement the lower steady-state baseplate temperature is arrival with increasing the number of perforated and lowest spacing ratio and maximum steady state in the base plate temperature with the flat fins and lowest number of fins and having heights inter fin spacing ratio (Dhere and Farkade, 2015). This study focused on fins designed with especially, device and make different holes in the fins and supplied different power on it to show the temperature distribution along the fins length and simulate with ansys program it's found that extended surfaces help to remove heat from the component. A thermal phenomenon of fins can be simulated using "non-linear thermal analysis" in ANSYS. Usage of vertical plate correlation on the fins surface is preferable and valid. A steady-state non-linear thermal analysis of fins is performed and results are compared with mathematical calculation. Both are matching within $+/-0.25$. The heat removal process is improved by creating perforations to the fin which is because of boundary layer detachment and reattachment process. Similarly having embossing on the fin surface is further improved the heat transfer. Max heat removal is observed in case of embossing with through hole. In the case of free convection, this perforation style can give the best performance in terms of temperature removal. These perforation styles, heat transfer and temperature reduction are in proportional to the number of perforations. It can be understood that maximum heat removal is possible with a greater number of perforations (Doreswamy and Hemanthb, 2017).

\section{MATERIALS AND METHODS}

Mathematical analysis of fin perforated: The heat transfer effectiveness and coefficient are increasing with the use the fun has a hole that known as perforated fins, the variable in the value of the surface area depends on the shape of the perforations (Jassem, 2013). In this study, $\left(\mathrm{N}_{\mathrm{X}}\right)$ represent the peroration number in the $\mathrm{x}$-direction $(\mathrm{L})$ and $\left(\mathrm{N}_{\mathrm{Y}}\right)$ in the $\mathrm{y}$-direction (W) assumed. The dimensions and number of circles are known for all fins (d) is the diameter of circular perforated and $(\mathrm{t})$ thickness of fin. The symbol $\left(\mathrm{A}_{c}\right)$ indicate to cross sectional area for perforated fins assumed and the dimension computes for any perforation. For the regular longitudinal fin with a rectangular shape (perforated fin) the area of the surface can be written as: 


$$
A_{f p}=A_{f}+N_{x} N_{y}\left(A_{p c}-2 A_{c}\right)
$$

to calculate the heat transfer in the surface area of the perforated fin $\left(\mathrm{A}_{\mathrm{fp}}\right)$ to that of the flat fin without perforated $\left(A_{f}\right)$ surface area ratio for the fins R.A.F is:

$$
\text { R.A.F }=\frac{A_{f p}}{A_{f}}=1+\frac{\pi \cdot b \cdot N_{z} \cdot N_{y}\left(t-\frac{d}{2}\right)}{\left(2 W \cdot L+W_{t}\right)}
$$

The next Eq. 3 computes the volume ratio for the material used for both fins perforated and non-perforated fins:

$$
\mathrm{RVF}=\frac{\mathrm{V}_{\mathrm{fp}}}{\mathrm{V}_{\mathrm{f}}}=1-\frac{\mathrm{N}_{\mathrm{x}} \cdot \mathrm{N}_{\mathrm{y}} \frac{\pi}{4} \mathrm{~d}_{2}}{\mathrm{~L} \cdot \mathrm{W}}
$$

Weight for the perforated fins is lower than the non-perforated fins, R.W.F has represented the ratio of weight for fins the ratio was written as:

$$
\text { R.W.F }=\frac{\mathrm{W}_{\mathrm{fp}}}{\mathrm{W}_{\mathrm{f}}}=1-\frac{\left(\mathrm{N}_{\mathrm{x}} \cdot \mathrm{N} \cdot \mathrm{y} \cdot \mathrm{A} \cdot \mathrm{c}\right)}{\mathrm{LW}}
$$

Experimental work: The experiments done by manufactured special instrument for this study. Figure 1 shows draw the device diagram. The experimental setting contains a heat source-sink provide with heating and system for saving data. The heat is produced within the heat sink by means of one heating the power of $670 \mathrm{~W}$. the results saved in the memory. The aluminum material used for unfaltering the heat sink, cylinder shape of $50.8 \mathrm{~mm}$ diameter and length $100 \mathrm{~mm}$. The cylinder is drilled by making a hole in the element the $670 \mathrm{~W}$, power released by the element that use as heating source. Five aluminum fins were fixed directly the fins have long $120,100 \mathrm{~mm}$ width and thickness $2 \mathrm{~mm}$. fins distributed into five groups as viewed Table 1.

A $50 \mathrm{~V}$ variable voltage transformer was used with the input voltage $220 \mathrm{~V}$ and $50 \mathrm{~Hz}$ and the output voltage $0-230 \mathrm{~V}, 20 \mathrm{~A}$ to set the voltage provided to the element used for heating (Fig. 1). Seventeen k-type heat sensors were used, distributed on the fins used in the experiment to measure the temperature at different locations. A thermodynamic sensor was flattened from the outer face of the main cylinder containing the thermal source to identify the base temperature of each fin. One thermometer was used to measure air temperature. The remaining fifteen thermocouple sensors were fixed into

\begin{tabular}{|c|c|c|}
\hline Types & Diameter (mm) & No. of circles \\
\hline 1 & - & Non \\
\hline 2 & 60 & 1 \\
\hline 3 & 30 & 2 \\
\hline 4 & 15 & 4 \\
\hline 5 & 7.5 & 8 \\
\hline
\end{tabular}
five fins that used in the study. Each sensor is installed

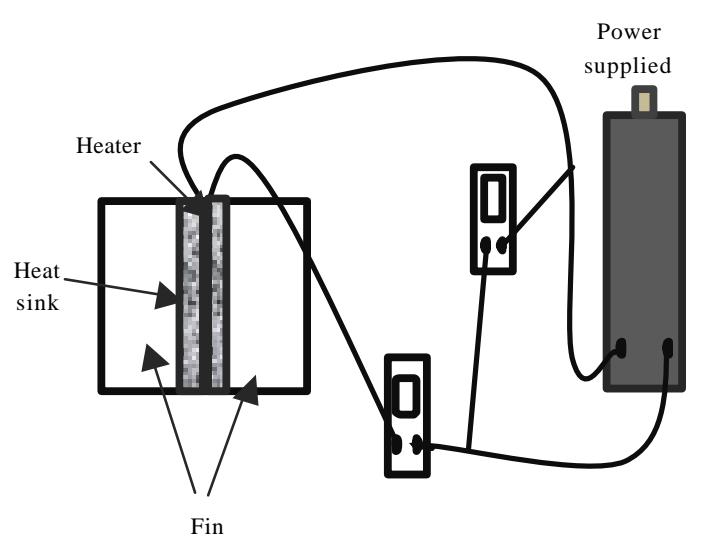

Fig. 1: Device drawing used is experiment

on the surface locations in the fins with an equal area $(40 \mathrm{~mm})$ in length. The machine continues for $60 \mathrm{~min}$ until the steady state of heat is reached.

\section{RESULTS AND DISCUSSION}

In this experimental study, the effect of the diameter of the hole on heat transfer of the fins was examined by the natural thermal type. The study was compared between the different diameter of the hole and then with the non-perforated fin. One of the factors affecting the efficiency of fins is temperature distributions which used to study comparison of different fins. Observed in the results the highest value of temperature was in the eight perforated fins and the distribution of low value of temperatures along the perforated fins with one circular hole for different values of the energy supplied. These results are shown in Fig. 2-4. Also, the change of temperature between the bottom of the fin and its tip is an important factor in recognizing the fin work which used to compare this factor with other fins. Through the same drawings in Fig. 2-4 it can be said, the maximum drop in temperature between the base of fin and tips also in single circular fin holes.

The RAF and diameter of perforations, the relation of them present in Fig. 5. R.A.F value is lower than one that showed in same figure. The heat lose average of the perforated fin depends on the two factors one of them is heat transfer coefficient another is fin area. In this study, the film heat transfer is assumed to be regular and the same during the study. The ratio RWF is curved as a 


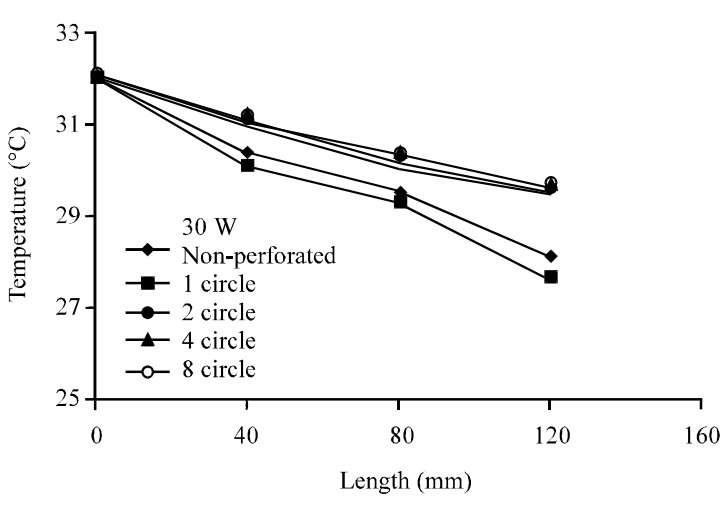

Fig. 2: Temperature distribution with length at $30 \mathrm{~W}$

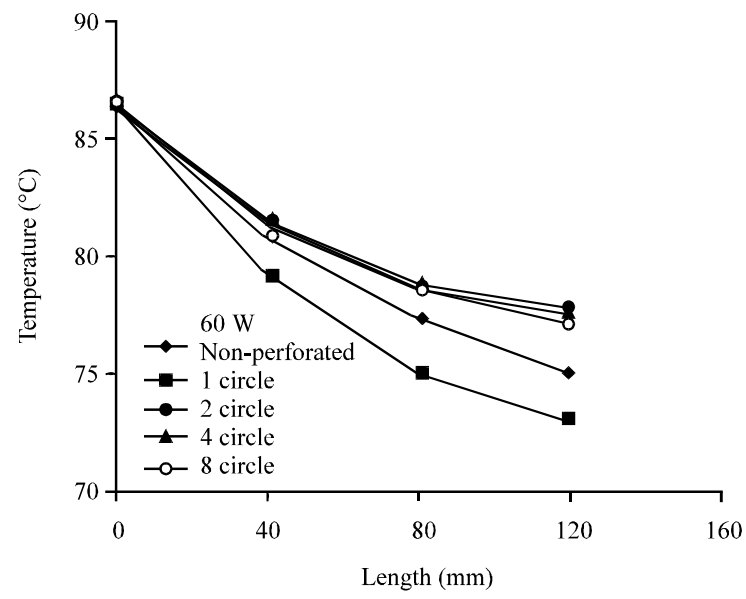

Fig. 3: Temperature distribution with length at $60 \mathrm{~W}$

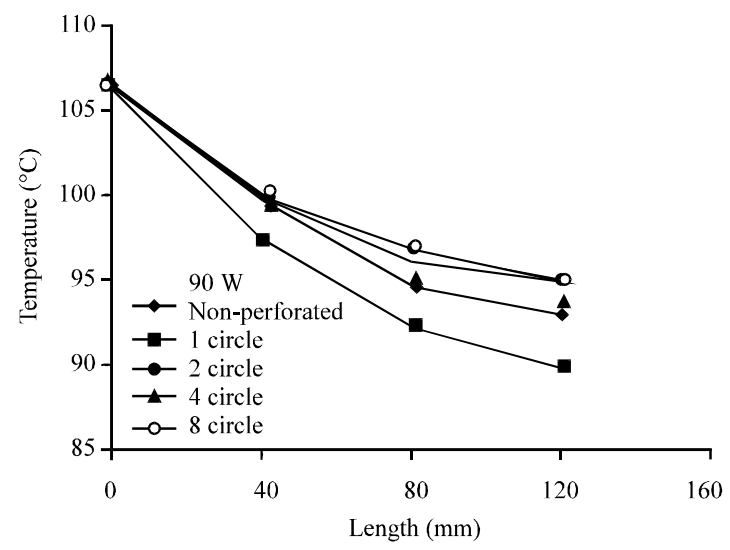

Fig. 4: Temperature distribution with length at $30 \mathrm{~W}$

function of the diameter of perforations in Fig. 6. The rate of ratio for weight decreasing, showed that the weight of the perforated fin persistent to decrease with increasing diameter of perforation fins. Figure 7 view the relationship between the volumes of perforated fins with the

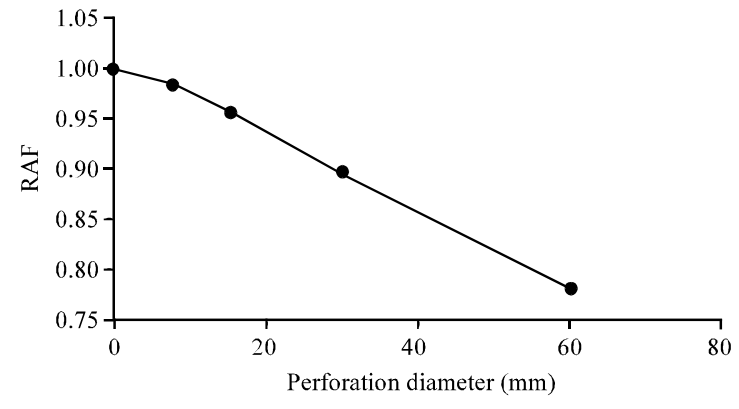

Fig. 5: The relation between (RAF) and perforations diameter

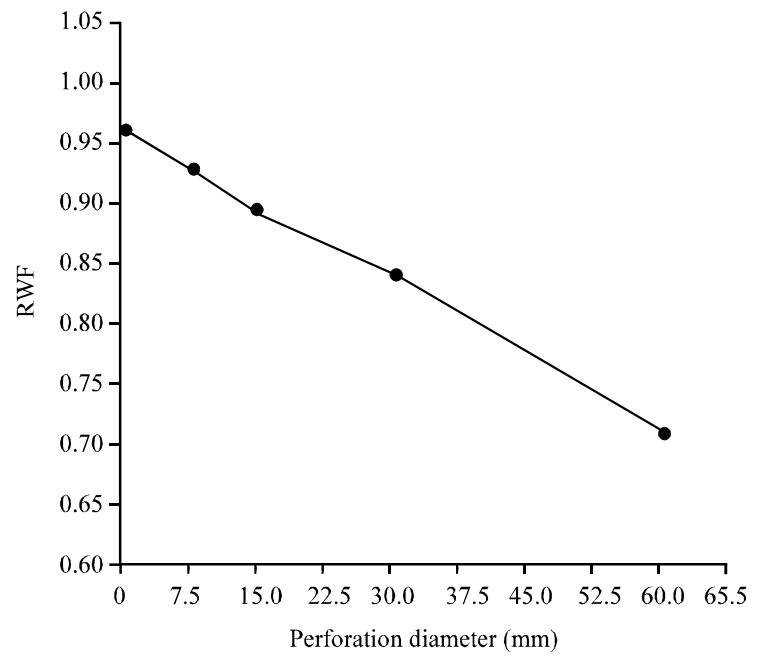

Fig. 6: The relation between (RWF) and perforation diameter

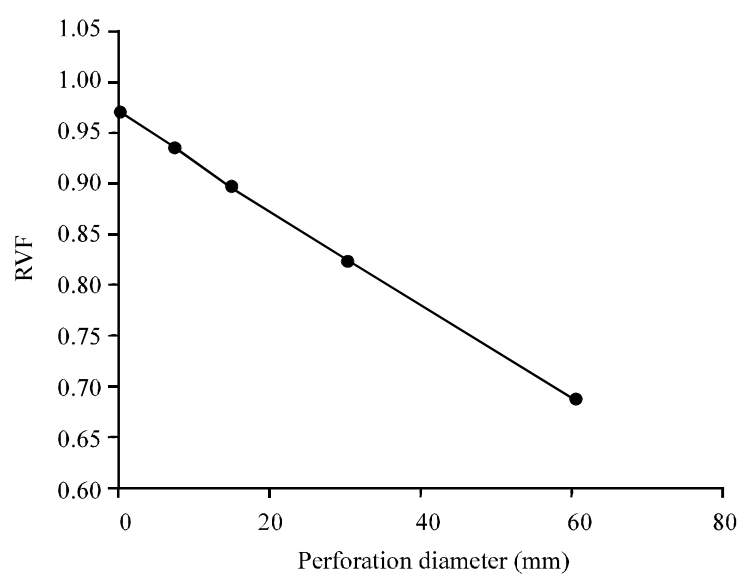

Fig. 7: The relation between (RVF) and perforations diameter

non-perforated its observed that the magnitude of RVF decreases with increase in the diameter of perforation. Figure 8 showed the temperature distribution along the 
(a) 1

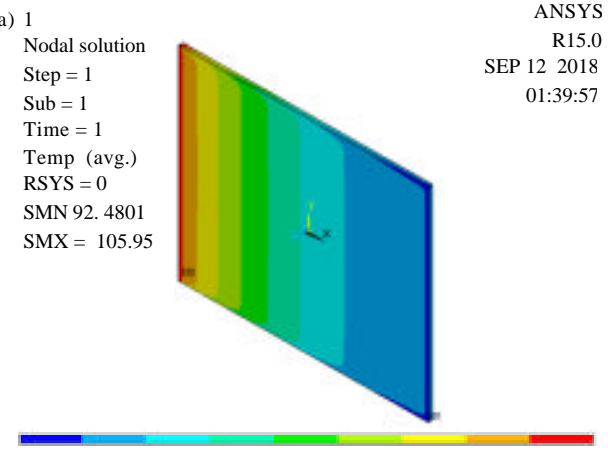

$\begin{array}{lrrrr}92.4801 & 95.4734 & 98.4667 & 101.46 & 104.453\end{array}$

(c) 1 Areas Type num

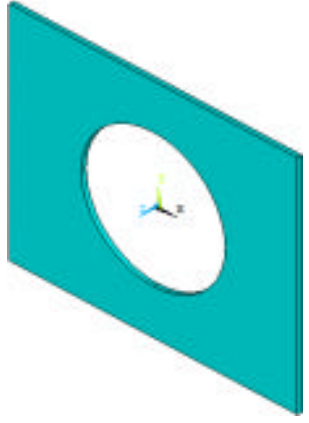

ANSYS SEP 12 R15. 2018

00:29:49

(e) 1 Areas Type num

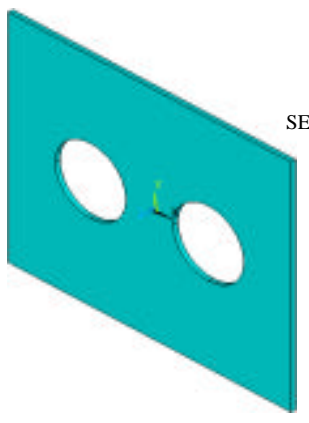

ANSYS

R15.0 SEP 12 2018
$00: 43: 11$

(g) 1 Areas Type num

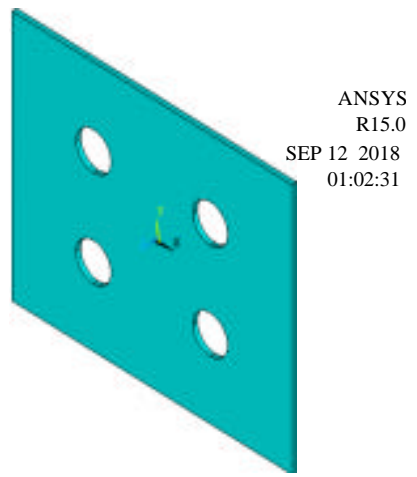

(b) 1
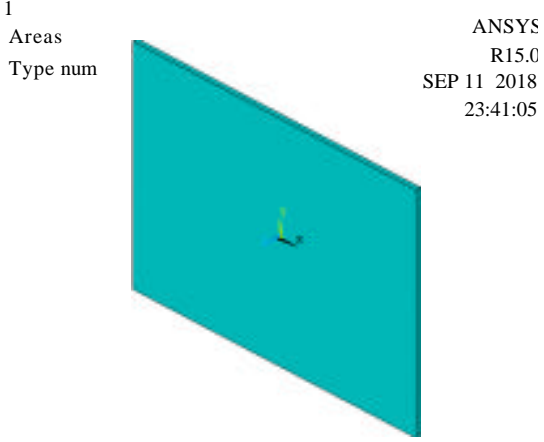

(d) 1

Nodal solution

Step $=1$

$\mathrm{Sub}=1$

Time $=1$

Temp (avg)

RSYS $=0$

SMN $=88.207$

SMX $=105.95$

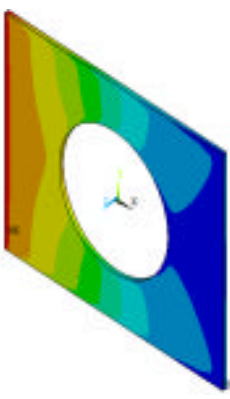

ANSYS SEP 122018 01:39:00

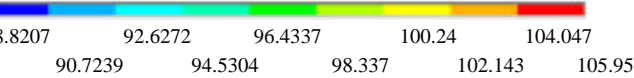

(f) 1

Nodal solution

Step $=1$

Sub $=1$

Time $=1$

Temp (avg.)

RSYS $=0$

$\mathrm{SMN}=94.6312$

SMX $=105.95$

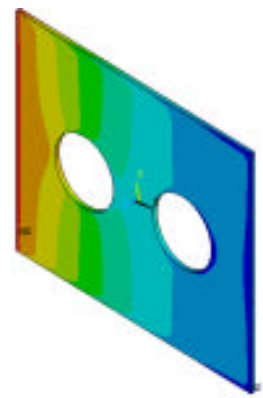

ANSYs

R15.C

SEP 122018

01:37:56

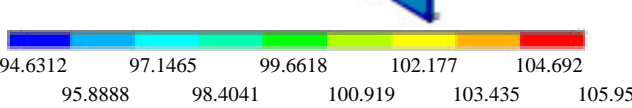

(h) 1

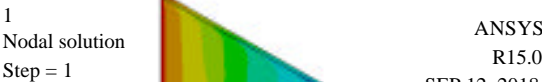

Step $=1$

Sub $=1$

Time $=1$

Temp (avg.)

RSYS $=0$

SMN $=94.4045$

SMX $=105.95$

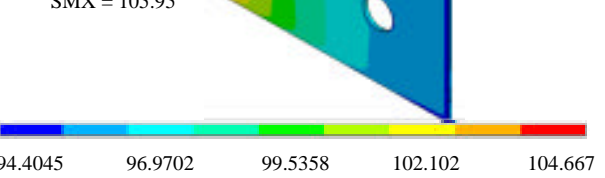

Fig. 8: Continue 

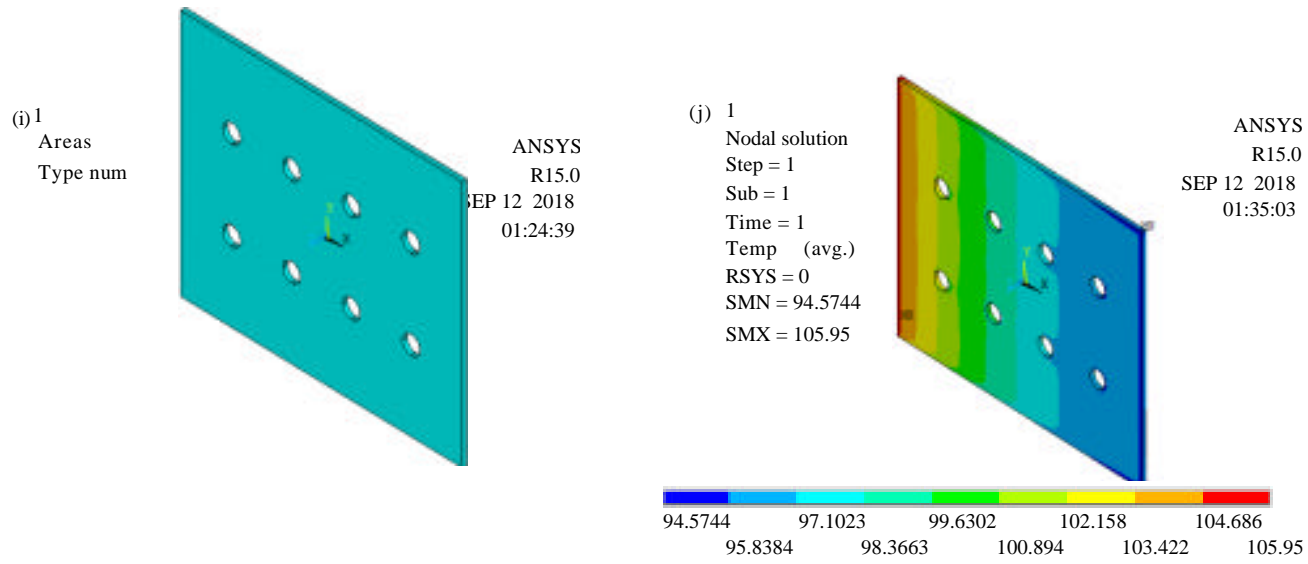

Fig. 8: a-j) Temperature distribution through the perforated fin and non perforated fin

Table 2: Result of ANSYS simulate program

\begin{tabular}{|c|c|c|c|c|}
\hline \multirow[b]{2}{*}{ Non-perforated fin } & \multicolumn{4}{|c|}{ No. of node } \\
\hline & $1(3112)$ & $2(3128)$ & $3(3154)$ & $4(3113)$ \\
\hline 30 & 31.900 & 30.567 & 29.697 & 29.333 \\
\hline 60 & 86.650 & 80.492 & 76.492 & 74.822 \\
\hline 90 & 105.95 & 98.958 & 94.392 & 92.480 \\
\hline 1 circle $(W)$ & $1(2470)$ & $2(2492)$ & $3(2512)$ & $4(2471)$ \\
\hline 30 & 31.900 & 30.196 & 29.135 & 28.641 \\
\hline 60 & 86.650 & 79.354 & 74.807 & 72.695 \\
\hline 90 & 105.95 & 96.995 & 91.414 & 88.821 \\
\hline 2 circle $(W)$ & $1(2826)$ & $2(2846)$ & $3(2867)$ & $4(2827)$ \\
\hline 30 & 31.900 & 30.676 & 30.080 & 29.747 \\
\hline 60 & 86.650 & 81.408 & 78.856 & 77.429 \\
\hline 90 & 105.95 & 99.516 & 96.384 & 94.631 \\
\hline 4 circle $(W)$ & $1(2998)$ & $2(3018)$ & $3(3040)$ & $4(2999)$ \\
\hline 30 & 31.900 & 30.638 & 30.024 & 29.704 \\
\hline 60 & 86.650 & 81.246 & 78.618 & 77.244 \\
\hline 90 & 105.95 & 99.317 & 96.091 & 94.405 \\
\hline 8 circle $(W)$ & $1(3070)$ & $2(3090)$ & $3(3110)$ & $4(3071)$ \\
\hline 30 & 31.900 & 30.640 & 30.082 & 29.736 \\
\hline 60 & 86.650 & 81.256 & 78.862 & 77.382 \\
\hline 90 & 105.95 & 99.329 & 96.391 & 94.574 \\
\hline
\end{tabular}

flat fin Fig. 8. Temperature drop along the length of fin for a perforated fin for $(1,2,4$ and 8 circle) it's showed in Fig. 2-4 the maximum drop at one perforated circular fin tip and minimum drop along the 8 circular perforated fins. Table 2 view all results for ANSYS simulate a program that is taken at four nodes the represented the fin length from base to tip. It observed the maximum temperature drop at one circular perforation.

\section{CONCLUSION}

The magnitude of decrease temperature in the one circular perforated fin length is always higher than the flat fin. The temperature drops along one circle of perforations and diameter $60 \mathrm{~mm}$, over than the perforated fin that include another diameter of perforations and diameters for all power supplied. Result showed temperature drop from maximum to minimum, respectively was (1 circle, non-perforated fin, 2 circles, 4 circles and 8 circles) fins. Along fin of perforated the temperature rate decrease with decreasing the dimension of the perforated fin. The RWF is decreased with an increase in the diameter of perforation because with lager perforation the fins lost more of weight. Compared the temperature drop by ANSYS program with the result for thermocouple experiment showed maximum error ratio of $4.54 \%$ at $30 \mathrm{~W}$. The error ratio between the experiment and simulate program was maximum at non-perforated fin was $(4.54 \%)$ at $30 \mathrm{~W}(2.43 \%)$ in non-perforated fin at $60 \mathrm{~W}$ and $(3.26 \%)$ in one circle perforated at $90 \mathrm{~W}$.

\section{ACKNOWLEDGEMENT}

The researcher would like to thank the Northern Technical University for helping to do this research and also thankful Dr. Ayad Alkaim for helping us for published this research.

\section{REFERENCES}

Al-Essa, D.A., 2012. Augmentation of heat transfer of a fin by rectangular perforations with aspect ratio of three. Intl. J. Mech. Appl., 2: 7-11.

AlEssa, A.H., A.M. Maqableh and S. Ammourah, 2009. Enhancement of natural convection heat transfer from a fin by rectangular perforations with aspect ratio of two. Intl. J. Phys. Sci., 4: 540-547.

Dhere, A.G. and H.S. Farkade, 2015. Computational analysis of triangular perforated fins in staggered arrangement. Intl. J. Sci. Technol. Eng., 1: 452-455.

Doreswamy, G.V. and J. Hemanthb, 2017. Study of convective heat transfer using rectangular fins with circular perforation. Imperial J. Interdiscip. Res., 3: 1532-1537. 
Ehteshum, M., M. Ali, M.Q. Islam and M. Tabassum, 2015. Thermal and hydraulic performance analysis of rectangular fin arrays with perforation size and number. Procedia Eng., 105: 184-191.
Jassem, R.R., 2013. Effect the form of perforation on the heat transfer in the perforated fins. Acad. Res. Intl., 4: 198-207.

Rajput, R.K., 2009. Heat and Mass Transfer. 3rd Edn., S. Chand Group, ?New Delhi, India, 